\title{
PENGARUH FAKTOR DETERMINAN TERHADAP HASIL TERAPI HIPERTENSI PASIEN PADA TIGA PUSKESMAS DI JAKARTA PUSAT
}

\author{
Andam Dewi Pertiwi ${ }^{1}$, Prih Sarnianto ${ }^{2}$, Hesty Utami Ramadaniati ${ }^{3}$ \\ 1,2,3 Fakultas Farmasi Universitas Pancasila, Jakarta, Indonesia \\ Email: andamdewi0216@gmail.com
}

\begin{abstract}
ABSTRAK
Hipertensi merupakan faktor risiko kejadian penyakit kardiovaskular sehingga tekanan darah perlu dikendalikan. Prevalensi pasien hipertensi yang tidak terkendali meningkat setiap tahunnya. Penelitian ini bertujuan untuk mengidentifikasi faktor determinan hipertensi terhadap keterkendalian hipertensi. Manfaat penelitian ini adalah untuk memberi edukasi kepada masyarakat terkait faktor yang mempengaruhi keterkendalian hipertensi. Penelitian dilakukan selama lima bulan melalui wawancara pasien hipertensi di 3 Puskesmas, yakni: Puskesmas Kecamatan Menteng, Tanah Abang, dan Johar Baru. Hasil wawancara dicocokkan dengan riwayat rujukan pasien. Ada 26 faktor yang digunakan untuk menganalisa determinan, meliputi: faktor sosiodemografi, biofisiologis, pola konsumsi, penggunaan kontrasepsi hormonal, aktivitas fisik, dan stres. Hasil analisis regresi multivariat menunjukan ada 2 faktor yang berpengaruh signifikan dan saling berkorelasi terhadap kondisi tekanan darah pasien yaitu riwayat penyakit jantung (odd ratio/OR $=0,091, \mathrm{p}=0,004$ ) dan rutinitas dalam melakukan aktivitas fisik $(\mathrm{OR}=10,647, \mathrm{p}=0,002)$. Pasien dengan riwayat penyakit jantung berpotensi 10,99 kali lipat memiliki hipertensi tidak terkendali dibandingkan dengan pasien tanpa riwayat penyakit jantung. Pasien yang rutin melakukan aktivitas fisik minimal 5 hari (durasi $150 \mathrm{menit} / \mathrm{minggu}$ ), memiliki potensi 10,647 kali lipat tekanan darahnya terkendali dibandingkan dengan pasien yang tidak rutin melakukannya.
\end{abstract}

Kata kunci: Faktor Determinan; Hipertensi; Hasil Terapi; Puskesmas.

\begin{abstract}
Hypertension has been known as risk factor of cardiovascular diseases necessitating the good control of blood pressure. The evident also shows the increased number of uncontrolled hypertensive patients. This study aimed to identify the determinants of controlled blood pressure in primary health centre hypertensive patients. The benefits of this research is to educated to public about factors that influence hypertension controlled. This research lasted for five months was conducted through patient interview of respondents meeting inclusion criteria in three primary health centres/PHC (PHC Menteng, PHC Tanah Abang, and PHC Johar Baru). Some data of the interview were validated by reviewing patient's medical record. There were 26 factors used to analyse the determinants which included sociodemographic, biophysiology, dietary consumption patterns, use of hormonal contraceptives, physical activity, and stress). The result of multivariate regression analysis revealed two significant determinants, namely the presence of cardiovascular diseases (odd ratio/OR $=0,091, \mathrm{P}$-value $=0,004$ ) and physical activity $(\mathrm{OR}=10,647, \mathrm{P}$-value $=0,002)$. Patients with history of cardiovascular disease had 10,99 times risk to experience uncontrolled hypertension compared with those with no history of the disease. In addition, patients with routine physical activity at least 5 days/week (150 minutes/week) were 10,647 times to have controlled blood pressured as opposed to their counterpants.
\end{abstract}

Keywords: Determinant Factors; Hypertension; Outcome of Therapy; Primary Health Centre.

\section{PENDAHULUAN}

Penyakit hipertensi selain dapat meningkatkan faktor risiko munculnya penyakit lain, prevalensinya juga cukup besar di Indonesia. Hasil Riset Kesehatan Dasar (Riskesdas) 2007 dan 2013 menunjukkan adanya peningkatan prevalensi hipertensi di Indonesia, yakni dari 7,6\% menjadi $9,5 \%{ }^{1}$ 
Riskesdas 2007 menyatakan bahwa prevalensi hipertensi tertinggi pada kelompok usia lanjut menurut Kabupaten/Kota ditemukan di Jakarta Pusat, sebesar $12,6 \%{ }^{2}$

Permasalahan yang terjadi tidak hanya terkait dengan tingginya prevalensi penyakit hipertensi, melainkan juga dengan meningkatnya kasus hipertensi yang tidak terkendali dari tahun ke tahun. Sebuah studi di Iran menyatakan bahwa terjadi peningkatan kasus hipertensi yang tidak terkendali sejak tahun 2001 hingga 2007. ${ }^{3}$ Cukup banyak faktor risiko yang berkaitan dengan keterkendalian hipertensi, diantaranya adalah usia, lingkungan tempat tinggal, tingkat pendidikan, riwayat keluarga yang menderita hipertensi, kebiasaan merokok, mengonsumsi garam berlebih, kurangnya aktivitas fisik, obesitas, adanya penyakit diabetes, serta kurangnya konsumsi sayur dan buah. ${ }^{3-5}$

Puskesmas (Pusat Kesehatan Masyarakat) merupakan sarana pelayanan kesehatan pertama, terdepan dalam melayani, dan dekat dengan masyarakat. Salah satu program Puskesmas yang menjadi fokus kinerjanya adalah pengendalian penyakit tidak menular (PTM), seperti hipertensi. Peneliti memilih 3 Puskesmas Kecamatan di wilayah Jakarta Pusat sebagai lokasi penelitian dengan jumlah pasien yang hampir seragam (yang dilakukan pengukuran tekanan darah oleh tenaga medis di Puskesmas), dan prevalensi kasus hipertensi di masyarakat yang cukup tinggi. Ketiga Puskesmas Kecamatan yang terpilih tersebut, yakni: Puskesmas Kecamatan Menteng, Tanah Abang, dan Johar Baru. ${ }^{6}$

Tujuan umum dari penelitian ini adalah untuk mengetahui faktor yang paling berpengaruh (determinan) terhadap keterkendalian hipertensi pasien di Puskesmas Kecamatan Menteng, Puskesmas Kecamatan Tanah Abang, dan Puskesmas Kecamatan Johar Baru agar dapat dievaluasi oleh pemerintah, tenaga kesehatan, maupun masyarakat umum sebagai upaya dalam menurunkan prevalensi hipertensi yang tidak terkendali.

\section{METODE PENELITIAN}

Penelitian ini menggunakan desain study cross sectional dengan mewawancarai 85 responden dari tiga Puskesmas Kecamatan di Jakarta Pusat menggunakan kuesioner yang telah lolos kaji etik dan tervalidasi. Isi kuesioner tersebut terkait faktor risiko hipertensi yang dialami atau dilakukan oleh responden selama beberapa waktu terakhir. Hasil wawancara dicocokkan dengan hasil terapi melalui data rekam medik responden. Parameter hasil terapi yang dilihat adalah ada atau tidaknya riwayat rujukan responden dalam setahun terakhir (menunjukkan keterkendalian kondisi hipertensi responden). Data dari kedua sumber tersebut (kuesoiner dan rekam medik) kemudian diolah secara statistika.

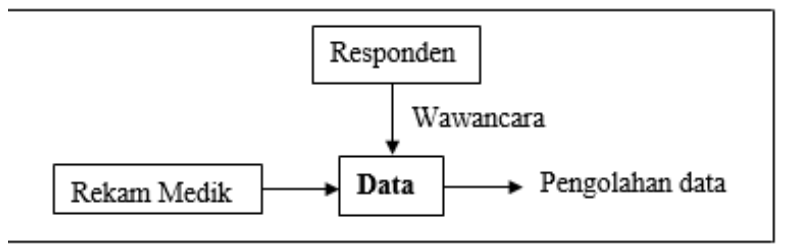

Gambar 1. Alur pengumpulan data penelitian

Kriteria inklusi dalam pemilihan responden, meliputi: pasien dengan hipertensi primer tingkat ringan hingga sedang, tanpa penyakit penyerta yang lebih berat dari hipertensi yang dideritanya, terdaftar di Puskesmas tempat penelitian selama setahun terakhir (terhitung sejak bulan Agustus 2017 hingga saat wawancara berlangsung) atau lebih, memiliki data rekam medik yang lengkap, dewasa (> 18 tahun), serta tidak dalam kondisi hamil. Sedangkan, kriteria eksklusi responden dalam penelitian ini, meliputi: pasien berpindah ke fasilitas kesehatan lain (tanpa rujukan dari dokter di Puskesmas tersebut dan tidak tercatat dalam data rekam medik) selama setahun terakhir dan/atau pasien tidak hadir saat proses wawancara berlangsung.

Dalam menentukan jumlah responden digunakan rumus Slovin, sebagai berikut:
$\mathrm{n}=\frac{\mathrm{N}}{1+\left(\mathrm{Nx \textrm {e } ^ { 2 }}\right)}$
Keterangan:
$\mathrm{n}$ : Jumlah sampel/responden
N: Populasi
e : Batas kesalahan yang ditoleransi 
Uji statistik yang digunakan pada penelitian ini adalah uji regresi logistik ganda yang dilakukan dengan menggunakan program SPSS dan ditunjang dengan program Microsoft Excel. $^{8}$

\section{HASIL PENELITIAN}

Tabel 1. Data sosiodemografi responden penelitian

\begin{tabular}{|c|c|c|}
\hline Variabel & Kategori & $\begin{array}{c}\text { Proporsi } \\
(\%)\end{array}$ \\
\hline \multirow[t]{5}{*}{ Umur } & 35-44 tahun & 3,5 \\
\hline & 45-54 tahun & 17,6 \\
\hline & 55-64 tahun & 47,1 \\
\hline & 65-74 tahun & 25,9 \\
\hline & $>74$ tahun & 5,9 \\
\hline \multirow[t]{2}{*}{ Jenis kelamin } & Laki-laki & 30,6 \\
\hline & Perempuan & 69,4 \\
\hline \multirow[t]{5}{*}{ Pendidikan } & Tidak tamat SD & 7,1 \\
\hline & SD & 25,9 \\
\hline & SMP & 17,6 \\
\hline & SMA & 34,1 \\
\hline & Perguruan Tinggi & 15,3 \\
\hline \multirow{2}{*}{$\begin{array}{l}\text { Status } \\
\text { pekerjaan }\end{array}$} & Bekerja & 20,0 \\
\hline & Tidak bekerja & 80,0 \\
\hline \multirow{2}{*}{$\begin{array}{l}\text { Status } \\
\text { perkawinan }\end{array}$} & Menikah & 67,1 \\
\hline & Cerai & 32,9 \\
\hline \multirow{2}{*}{$\begin{array}{l}\text { Waktu tempuh } \\
\text { menuju } \\
\text { Puskesmas }\end{array}$} & $\leq 0,5$ jam & 91,8 \\
\hline & $>0,5 \mathrm{jam}$ & 8,2 \\
\hline \multirow{7}{*}{$\begin{array}{l}\text { Suku dan } \\
\text { budaya }\end{array}$} & Jawa & 22,4 \\
\hline & Sunda & 12,9 \\
\hline & Batak & 4,7 \\
\hline & Madura & 1,2 \\
\hline & Betawi & 40,0 \\
\hline & Minangkabau & 11,8 \\
\hline & Lainnya & 7,1 \\
\hline \multirow{5}{*}{$\begin{array}{l}\text { Status } \\
\text { ekonomi }\end{array}$} & Kuintil 1 & 20,0 \\
\hline & Kuintil 2 & 23,5 \\
\hline & Kuintil 3 & 16,5 \\
\hline & Kuintil 4 & 25,9 \\
\hline & Kuintil 5 & 14,1 \\
\hline
\end{tabular}

Data sosiodemografi responden ditunjukkan pada Tabel 1. Dari segi usia, umumnya umur responden berusia 55-64 tahun. Peluang hipertensi cenderung meningkat seiring bertambahnya usia. ${ }^{1,9}$ Namun, pada penelitian ini diketahui jumlah responden yang berusia diatas 64 tahun semakin berkurang karena responden tersebut sulit untuk memeriksakan diri ke Puskesmas akibat keterbatasan kemampuan fisik mereka. Berdasarkan jenis kelamin, umumnya responden berjenis kelamin perempuan. Hal tersebut dapat disebabkan oleh hormon-homon yang ada di dalam tubuh perempuan..$^{1,9-12}$

Tingkat pendidikan responden didominasi oleh lulusan SMA. Meningkatnya pendidikan pasien tidak selalu sebanding dengan potensi munculnya hipertensi, ataupun sebaliknya. ${ }^{1}$ Sebanyak $80 \%$ responden tidak bekerja, umumnya mereka adalah pensiunan dan ibu rumah tangga. Beberapa penelitian menemukan bahwa kelompok responden yang tidak bekerja memiliki prevalensi hipertensi yang lebih tinggi dibandingkan dengan kelompok responden yang bekerja. ${ }^{1,11}$

Dilihat dari status perkawinan, responden terbanyak ada pada kategori menikah. Hal ini tidak sesuai dengan hasil penelitian yang dilakukan oleh Zamhir Setiawan, yang menyatakan bahwa responden yang berstatus belum menikah atau bercerai memiliki prevalensi hipertensi yang lebih besar dibandingkan dengan kelompok responden yang berstatus menikah. ${ }^{12}$

Sebanyak $91,8 \%$ responden bertempat tinggal tidak jauh dari Puskesmas, dengan waktu tempuh tidak lebih dari setengah jam. Terbentuknya jaringan Puskesmas Kecamatan dan Kelurahan telah menjangkau masyarakat di wilayah sekitarnya. Mayoritas respoden merupakan suku Betawi. Hal ini dapat dipengaruhi oleh lokasi Puskesmas tempat penelitian yang berada di Jakarta Pusat, dimana masih banyak penduduk asli Jakarta (suku Betawi) yang menetap. Sedangkan, suku atau budaya lainnya yang menjadi responden penelitian ini berasal dari Jawa, Sunda, Batak, Madura, Minangkabau, Bengkulu, Makassar, Bugis, Palembang, serta Tiongkok. 
Status ekonomi pada penelitian ini dihitung berdasarkan kuintil pengeluaran responden per bulan. Kuintil 1 merupakan $20 \%$ pengeluaran terendah, kuintil 2 merupakan $20 \%$ pengeluaran kedua terendah, kuintil 3 merupakan $20 \%$ pengeluaran ketiga terendah, kuintil 4 merupakan $20 \%$ pengeluaran keempat terendah, dan kuintil 5 yang merupakan $20 \%$ pengeluaran tertinggi. Dari penelitian ini didapatkan persentase kuintil yang hampir seragam dari kuintil 1 hingga kuintil 5. Hanya saja persentase terbesar ada pada kuintil 4 .

Tabel 2. Data biofisiologis responden penelitian

\begin{tabular}{|l|l|c|}
\hline \multicolumn{1}{|c|}{ Variabel } & Kategori & $\begin{array}{c}\text { Proporsi } \\
(\%)\end{array}$ \\
\hline \multirow{2}{*}{$\begin{array}{l}\text { Indeks Massa Tubuh } \\
\text { (IMT) }\end{array}$} & $\geq 25$ & 67,1 \\
\cline { 2 - 3 } & $<25$ & 32,9 \\
\hline Kadar kolesterol & Normal & 74,1 \\
\cline { 2 - 3 } & Batas & 18,8 \\
\cline { 2 - 3 } & Tinggi & 7,1 \\
\hline \multirow{2}{*}{$\begin{array}{l}\text { Riwayat penyakit } \\
\text { jantung }\end{array}$} & Pernah & 14,1 \\
\cline { 2 - 3 } & Tidak & 85,9 \\
\hline Penyakit ginjal & Ada & 2,4 \\
\cline { 2 - 3 } & Tidak ada & 97,6 \\
\hline \multirow{2}{*}{ Riwayat hipertiroid } & Pernah & 1,2 \\
\cline { 2 - 3 } & Tidak & 98,8 \\
\hline \multirow{2}{*}{$\begin{array}{l}\text { Penyakit diabetes } \\
\text { Riwayat keluarga }\end{array}$} & Ada & 40,0 \\
\cline { 2 - 3 } $\begin{array}{l}\text { yang menderita } \\
\text { hipertensi }\end{array}$ & Tidak ada & 60,0 \\
\cline { 2 - 3 } & Ada & 61,2 \\
\hline
\end{tabular}

Berdasarkan data biofisiologis responden, umumnya responden memiliki nilai IMT $\geq 25$, yang menandakan bahwa responden tersebut mengalami obesitas. Prevalensi hipertensi pada pasien dengan obesitas cenderung lebih besar dibandingkan dengan yang tidak obesitas. ${ }^{11,12}$ Sebanyak $74,1 \%$ responden memiliki kadar kolesterol yang normal, walaupun sebenarnya hiperkolesterol menjadi salah satu fakor risiko pencetus munculnya hipertensi. ${ }^{12}$ Sama seperti kadar kolesterol, riwayat penyakit jantung juga tidak selalu ditemui pada responden penelitian ini.

Mayoritas responden tidak mengalami penyakit ginjal. Begitu pula dengan riwayat hipertiroid yang umumnya tidak pernah dialami oleh responden. Di sisi lain, mayoritas responden tidak memiliki penyakit diabetes. Keluarga dengan riwayat penyakit hipertensi banyak dimiliki oleh responden. Responden yang memiliki riwayat keluarga hipertensi berpeluang lebih besar mendapatkan hipertensi dibandingkan dengan yang tidak memiliki riwayat keluarga hipertensi. ${ }^{9}$

Tabel 3. Data pola konsumsi responden penelitian

\begin{tabular}{|c|c|c|}
\hline Variabel & Kategori & $\begin{array}{l}\text { Proporsi } \\
(\%)\end{array}$ \\
\hline \multirow{2}{*}{$\begin{array}{l}\text { Konsumsi sayur } \\
\text { dan buah }\end{array}$} & $\geq 5$ porsi/hari & 50,6 \\
\hline & $<5$ porsi/hari & 49,4 \\
\hline \multirow{2}{*}{$\begin{array}{l}\text { Konsumsi } \\
\text { makanan asin }\end{array}$} & Setiap hari & 50,6 \\
\hline & Tidak setiap hari & 49,4 \\
\hline \multirow{2}{*}{$\begin{array}{l}\text { Konsumsi } \\
\text { makanan tinggi } \\
\text { lemak }\end{array}$} & Setiap hari & 20,0 \\
\hline & Tidak setiap hari & 80,0 \\
\hline \multirow{2}{*}{$\begin{array}{l}\text { Konsumsi } \\
\text { alkohol dalam } \\
\text { sebulan terakhir }\end{array}$} & $\mathrm{Ya}$ & 7,1 \\
\hline & Tidak & 92,9 \\
\hline \multirow{2}{*}{$\begin{array}{l}\text { Konsumsi } \\
\text { minuman } \\
\text { berkafein }\end{array}$} & Setiap hari & 40,0 \\
\hline & Tidak setiap hari & 60,0 \\
\hline \multirow{3}{*}{$\begin{array}{l}\text { Konsumsi } \\
\text { vitamin atau } \\
\text { suplemen }\end{array}$} & Tidak pernah & 14,1 \\
\hline & $\begin{array}{l}\text { Pernah, tapi saat } \\
\text { ini tidak }\end{array}$ & 16,5 \\
\hline & $\begin{array}{l}\text { Mengonsumsi } \\
\text { hingga kini }\end{array}$ & 69,4 \\
\hline \multirow{3}{*}{$\begin{array}{l}\text { Konsumsi } \\
\text { bawang putih }\end{array}$} & Tidak pernah & 11,8 \\
\hline & $\begin{array}{l}\text { Pernah, tapi saat } \\
\text { ini tidak }\end{array}$ & 4,7 \\
\hline & $\begin{array}{l}\text { Mengonsumsi } \\
\text { hingga kini }\end{array}$ & 83,5 \\
\hline \multirow[t]{4}{*}{ Merokok } & Setiap hari & 8,2 \\
\hline & Kadang-kadang & 4,7 \\
\hline & Mantan perokok & 15,3 \\
\hline & Bukan perokok & 71,8 \\
\hline
\end{tabular}


Dilihat dari pola konsumsi sayur dan buah, terlihat antara responden yang rutin mengonsumsi sayur dan buah lebih dari atau sama dengan 5 porsi sehari jumlahnya tidak berbeda jauh dengan responden yang konsumsi sayur dan buahnya tidak sampai 5 porsi sehari. Hal serupa juga terlihat pada pola konsumsi makanan asin atau tinggi natrium. Sedangkan, untuk konsumsi makanan tinggi lemak, sebanyak $80 \%$ responden tidak setiap hari mengonsumsinya. Walaupun pada umumnya, semakin sering mengonsumsi makanan berlemak, maka prevalensi hipertensinya cenderung lebih tinggi dibandingkan dengan yang jarang mengonsumsinya. ${ }^{13}$

Sebanyak $92,9 \%$ responden tidak mengonsumsi alkohol dalam sebulan terakhir. Alkohol yang dimaksud yakni minuman serta makanan yang mengandung alkohol seperti tape dan durian. Sedikitnya responden yang mengonsumsi alkohol dikarenakan minuman beralkohol tidak lazim dikonsumsi oleh masyarakat Indonesia, khususnya karena aturan agama tertentu yang mayoritas dianut oleh masyarakat Indonesia. Adapun untuk makanan yang mengandung alkohol jarang dikonsumsi karena umumnya hanya disajikan secara musiman atau di hari-hari khusus tertentu. Walaupun begitu, diketahui bahwa konsumsi alkohol dapat meningkatkan risiko hipertensi. ${ }^{10}$

Jumlah responden yang mengonsumsi minuman berkafein setiap hari hanya sebanyak $40 \%$, baik itu berupa kopi maupun teh. Sebanyak $69,4 \%$ responden rutin mengonsumsi vitamin atau suplemen hingga saat ini, baik berupa herbal maupun non-herbal. Konsumsi bawang putih diketahui dapat menurunkan tekanan darah. ${ }^{11,14}$ Berbagai metode pengolahan bawang putih sebagai konsumsi khusus penderita hipertensi sudah diperkenalkan sejak dulu, mulai dari dikonsumsi langsung, maupun dijadikan seduhan. Pada penelitian ini, responden yang masih rutin mengonsumsi bawang putih di luar penggunaannya sebagai bumbu dapur sebesar 83,5\%. Mereka mengonsumsi bawang putih didasarkan pada kemanfaatan dan keamanannya dalam menunjang terapi hipertensi.

Sebanyak $71,8 \%$ responden merupakan bukan perokok. Hal ini dapat dikarenakan mayoritas responden adalah wanita, dimana cukup jarang wanita Indonesia yang mengonsumsi rokok atau bahan olahan tembakau lainnya. Walaupun begitu, kebiasaan merokok terbukti menjadi salah satu faktor risiko munculnya hipertensi. ${ }^{13}$

Tingginya prevalensi hipertensi juga dipengaruhi oleh penggunaan kontrasepsi hormonal pada wanita. Beberapa jenis kontrasepsi hormonal yang digunakan oleh masyarakat Indonesia, meliputi: pil KB, suntik, dan susuk. Pada penelitian ini, hanya $23,73 \%$ responden wanita yang menggunakan kontrasepsi hormonal, dan sisanya merupakan pengguna kontrasepsi jenis IUD (Intra Uterine Device), steril, atau tidak pernah menggunakan alat kontrasepsi sama sekali.

Rutinitas dalam melakukan aktivitas fisik diyakini berpengaruh terhadap prevalensi hipertensi. Responden dinyatakan aktif secara fisik jika melakukan aktivitas fisik minimal 30 menit per hari, selama minimal 5 hari dalam seminggu. Aktivitas fisik ini tidak hanya berupa olahraga rutin, melainkan juga kegiatan seharihari. ${ }^{1}$ Pada penelitian ini, sebanyak $76,5 \%$ responden dinyatakan aktif secara fisik. Mereka didominasi oleh ibu rumah tangga yang terbiasa dengan aktivitas menyapu, mengepel, mencuci, dan sebagainya, yang dilakukan hampir setiap hari.

Berdasarkan data tingkat stres responden yang diukur menggunakan Self Reporting Questionnaire (SRQ), sebanyak 76,5\% responden tidak mengalami stres. Pengaruh stres terhadap hipertensi sendiri diduga karena aktivitas saraf simpatis yang dapat meningkatkan tekanan darah bila seseorang merasa terancam. ${ }^{10}$ 


\section{PEMBAHASAN}

Tabel 4. Variabel bebas yang lolos uji analisis bivariat

\begin{tabular}{|l|l|c|c|}
\hline No. & \multicolumn{1}{|c|}{ Variabel } & Sig. & $\begin{array}{c}\text { Koefisien } \\
\text { Korelasi }\end{array}$ \\
\hline 1. & $\begin{array}{l}\text { Riwayat penyakit } \\
\text { jantung }\end{array}$ & 0,000 & $-0,389$ \\
\hline 2. & Penyakit ginjal & 0,004 & $-0,310$ \\
\hline 3. & $\begin{array}{l}\text { Riwayat } \\
\text { hipertiroid }\end{array}$ & 0,045 & $-0,218$ \\
\hline 4. & Merokok & 0,092 & 0,184 \\
\hline 5. & $\begin{array}{l}\text { Melakukan } \\
\text { aktivitas fisik }\end{array}$ & 0,000 & 0,416 \\
\hline 6. & Stres & 0,010 & $-0,277$ \\
\hline
\end{tabular}

Dari hasil uji analisis bivariat, ada 6 variabel yang dapat diseleksi lebih lanjut untuk uji analisis multivariat, yakni: variabel Riwayat penyakit jantung, Penyakit ginjal, Riwayat hipertiroid, Melakukan aktivitas fisik, Stres, dan Merokok. Selanjutnya, dilakukan seleksi dan uji analisis multivariat regresi ganda sehingga didapatkan hasil akhir uji yang menyisakan dua variabel bebas yang berpengaruh terhadap kondisi keterkendalian hipertensi dan saling mempengaruhi variabel bebas lainnya, yakni variabel Riwayat penyakit jantung dan Melakukan aktivitas fisik.

Tabel 5. Hasil akhir uji analisis multivariat regresi logistik ganda

\begin{tabular}{|c|l|c|c|}
\hline No. & \multicolumn{1}{|c|}{ Variabel } & Sig. & OR \\
\hline 1. & $\begin{array}{l}\text { Riwayat penyakit } \\
\text { jantung }\end{array}$ & 0,004 & 0,091 \\
\hline 2. & $\begin{array}{l}\text { Melakukan aktivitas } \\
\text { fisik }\end{array}$ & 0,002 & 10,647 \\
\hline
\end{tabular}

Pada variabel Riwayat penyakit jantung diketahui nilai OR sebesar 0,091, menunjukkan bahwa pasien yang memiliki riwayat penyakit jantung berpotensi 10,99 (1 : 0,091; koefisien korelasi bernilai negatif) kali lipat untuk dirujuk ke rumah sakit karena tekanan darahnya tidak terkendali dibandingkan dengan pasien yang tidak memiliki riwayat penyakit jantung. Hasil ini sejalan dengan penelitian yang dilakukan oleh Alireza Khosravi dkk yang menyatakan bahwa adanya penyakit kardiovaskuler berpengaruh terhadap kondisi hipertensi pasien sehingga tekanan darahnya tidak terkendali dengan nilai OR sebesar $1,25 .^{3}$

Sementara itu, pada faktor rutinitas dalam melakukan aktivitas fisik, nilai OR yang didapatkan sebesar 10,647. Hal ini menunjukkan bahwa pasien yang rutin melakukan aktivitas fisik minimal 5 hari dengan total lamanya aktivitas sebesar 150 menit/minggu, memiliki potensi 10,647 kali lipat tekanan darahnya lebih terkendali dibandingkan dengan pasien yang tidak rutin dalam melakukan aktivitas fisik tersebut. Hasil ini juga sejalan dengan hasil penelitian yang dilakukan oleh Li Yang dkk dengan nilai OR sebesar 0,8; Alireza Khosravi dkk dengan nilai OR sebesar 1,09; dan Nomazulu Mpande dkk dengan nilai OR sebesar 0,23. Ketiga penelitian itu menyatakan bahwa kurangnya aktivitas fisik menyebabkan kondisi hipertensi penderitanya menjadi tidak terkendali. ${ }^{3-5}$

\section{SIMPULAN}

Faktor yang memiliki pengaruh signifikan (Sig. $\leq 0,05)$ dan saling berkaitan dengan faktor lain terhadap keterkendalian hipertensi pasien di Puskesmas Kecamatan Menteng, Tanah Abang, dan Johar Baru, meliputi: riwayat penyakit jantung (dengan Sig: 0,004 dan OR: 0,091) dan rutinitas pasien dalam melakukan aktivitas fisik (dengan Sig: 0,002 dan OR: 10,647).

\section{SARAN}

Bagi penelitian selanjutnya, diperlukan jumlah responden yang lebih banyak agar hasil penelitian lebih akurat, dan sebagai evaluasi dari hasil penelitian ini, maka pemerintah harus mengoptimalkan program-program yang mengandalkan aktivitas fisik seperti senam jantung atau senam rutin lainnya di fasilitas-fasilitas yang dekat oleh masyarakat, salah satunya yakni Puskesmas. 


\section{UCAPAN TERIMA KASIH}

Kami mengucapkan terima kasih kepada Kepala Puskesmas Kecamatan Menteng, Tanah Abang, dan Johar Baru yang telah memperkenankan peneliti dalam pengambilan data di Puskesmas tersebut.

\section{DAFTAR PUSTAKA}

1. Badan Penelitian dan Pengembangan Kementerian Kesehatan RI. Riset kesehatan dasar. Jakarta: Kementerian Kesehatan RI; 2013.

2. Purnama DS, Prihartono NA. Prevalensi hipertensi dan faktor-faktor yang berhubungan dengan kejadian hipertensi pada lansia di posyandu lansia wilayah Kecamatan Johar Baru Jakarta Pusat tahun 2013. 2013;2.

3. Khosravi A, Pourheidar B, Roohafza $\mathrm{H}$, Moezzi M, Mousavi M, Hajiannejad A, et al. Evaluating factors associated with uncontrolled hypertension: Isfahan cohort study, Iran. ARYA Atheroscler. 2014;10(6):311-8.

4. Yang L, Xu X, Yan J, Yu W, Tang X, $\mathrm{Wu} \mathrm{H}$, et al. Analysis on associated factors of uncontrolled hypertension among elderly hypertensive patients in Southern China : a community-based, cross-sectional survey. BMC Public Health. 2014;14(903):1-8.

5. Mpande N, Chinamasa CF, Manangazira P, Mungati M, Takundwa L, Gombe NT, et al. Factors associated with uncontrolled high blood pressure amongst patients with hypertension at Harare Central Hospital in Zimbabwe. JHC. 2016;2(2):15-24.

6. Suku Dinas Kesehatan Jakarta Pusat. Profil kesehatan Kota Administrasi Jakarta Pusat 2016. Jakarta; 2017.

7. Qomari R. Teknik penelusuran analisis data kuantitatif dalam penelitian kependidikan. J Pemikir Altern Pendidik. 2009;14(3):1-11.

8. Hastomo SP. Modul analisis data biostatistik. Depok: Universitas Indonesia; 2016. 162-219 p.

9. Hasurungan J. Faktor-faktor yang berhubungan dengan hipertensi pada lansia di Kota Depok tahun 2002. Universitas Indonesia; 2002.

10. Rahajeng E, Tuminah S. Prevalensi hipertensi dan determinannya di Indonesia. Maj Kedokt Indon. 2009;59(12):580-7.

11. Basuki B, Setianto B. Age, body posture, daily working load, past antihypertensive drugs and risk of hypertension: A rural Indonesian study. Med J Indones. 2001;10(I):2933.

12. Setiawan Z. Prevalensi dan determinan hipertensi di Pulau Jawa tahun 2004. Kesmas. 2006;1(2):5762.

13. Aisyiyah FN. Faktor risiko hipertensi pada empat kabupaten/kota dengan prevalensi hipertensi tertinggi di Jawa dan Sumatera. Institut Pertanian Bogor; 2009.

14. Mohanis. Pemberian air seduhan bawang putih terhadap penurunan tekanan darah. J IPTEKS Terap. 2015;9:117-25. 